Chapter 10

\title{
Dyspepsia and Opioid-Induced Bowel Dysfunction: The Role of Opioid Receptor Antagonists
}

Wojciech Leppert

Additional information is available at the end of the chapter

http://dx.doi.org/10.5772/56624

\section{Introduction}

Opioid analgesics are commonly and in most cases effectively used to manage chronic pain of moderate to severe intensity. Apart from analgesia, opioids exert numerous adverse effects, several of which impact the gastrointestinal (GI) tract. The chronic use of opioid analgesics in fact is commonly associated with adverse effects on the gastrointestinal tract. [1] Opioid-induced bowel dysfunction (OIBD) comprises gastrointestinal symptoms such as dry mouth, anorexia, gastroesophageal reflux (GERD), delayed digestion, abdominal pain, flatulence, bloating, nausea, vomiting, and constipation with hard stool and incomplete evacuation. Further, side effects from long-term opioid therapy may result in more serious intestinal complications such as faecal impaction with overflow diarrhea and incontinence, pseudo-obstruction (causing anorexia, nausea and vomiting), disturbance of drug absorption, and urinary retention and incontinence. OIBD may also lead to inappropriate opioid dosing and in consequence, insufficient analgesia. As a result, OIBD significantly deteriorate patients' quality of life and compliance with their treatment. Approximately one-third of patients treated with opioid analgesics do not adhere to the prescribed opioid regimen or simply quit the treatment due to OIBD symptoms [2].

Several strategies have been advocated to prevent or treat OIBD. Use of traditional laxatives is limited by their effectiveness, yet conveys their own adverse effects. Other possibilities comprise an opioid switch or changing the opioid administration route. New therapies now target opioid receptors in the gut as they represent a main source of OIBD symptoms. A combination of an opioid and opioid antagonist (oxycodone/naloxone) in prolonged release tablets and purely peripherally acting opioid receptor antagonist (methylnaltrexone) available in subcutaneous injections are currently available treatment options. This chapter reviews the pathophysiological basis and possible treatment strategies for OIBD. 


\section{Pathophysiological mechanism of opioid-induced bowel dysfunction}

Opioids produce widespread effects throughout the gastrointestinal tract though several central and peripheral mechanisms. Such effects are a mixture of inhibitory and excitatory actions. Opioid peptides and their receptors are found throughout the gastrointestinal tract, especially in the gastric antrum and proximal duodenum. The basis for OIBD is therefore complex. The peripheral opioid effect on $\mu$-opioid receptors in the gut wall likely plays a major role, but central effects may also be important [3]. $\mu$-opioid receptors at a high density reside in neurons of myenteric and submucosal plexus and immune cells in the lamina propria [4]. Opioid receptors (predominantly $\mu$, also $\kappa$ and $\delta$ ) are located in the gut wall in the myenteric plexus and in the submucosal plexus. The former are responsible for gut motility and the latter for secretion. These $\mu$-opioid receptors are activated in the wall of the stomach, small and large intestine by both endogenous (e.g. enkephalins, endorphins and dynorphins) and exogenous (e.g. morphine, oxycodone, methadone) opioids and modify gastrointestinal function. Activation of $\mu$-opioid receptors inhibits excitatory and inhibitory neural pathways within the enteric nervous system that coordinates motility. Inhibition of excitatory neural pathways depresses peristaltic contractions. On the other hand, the blockade of inhibitory neural pathways increases gut muscle activity, elevates resting muscle tone, and results in spasm and non-propulsive motility patterns. These mechanisms give rise to delayed gastric emptying and slowed intestinal transit [5].

Activation of opioid receptors in the submucosa inhibits water and electrolyte secretion into the gut lumen and increases fluid absorption from the intestine and accelerates blood flow in the gut wall [6]. Opioids increase activity in the sympathetic nervous system and thereby decrease secretion. Endocrine cells located in the epithelium also may play a role in regulating motor activity and secretion in the gut. Interms of motility, peripheral $\mu$-opioid receptors inhibit intestinal transit independent of central $\mu$-opioid receptors [7]. Moreover, opioids increase ileocaecal and anal sphincter tones and impair defecation reflex through reduced sensitivity to distension and increased internal anal sphincter tone [8]. Morphine administration leads to sphincter contraction and to a decreased emptying of pancreatic juice and bile [9], which may impair digestion. The anal sphincter dysfunction is an important factor in the sensation of anal blockage $[10,11]$.

The central mechanism of opioid effects on the gastrointestinal tract is supported by the results of animal studies in which intracerebroventricular administration of morphine inhibited GI propulsion [12]. This effect was reversed by intracerebroventricular administration of naloxone [13] and vagotomy [14]. Intrathecal administration of morphine reduced gastroduodenal motility while intramuscular morphine gave additional effects. Thus, it seems that both central and peripheral opioid effects play a role in opioid GI effects [15]. The indirect evidence of both central and peripheral components of opioid effects on bowel function may be the observed $50-60 \%$ response rate to the treatment of OIBD with methylnaltrexone (MNTX), which displays only peripheral $\mu$-opioid receptor antagonist effect in the treatment of patients with OIBD $[16,17]$. The stool remains in the gut lumen for a longer time, allowing greater absorption of fluid. Enhanced absorption combined with opioid inhibition 
of secretomotor neurons in the epithelium of the gut [18] leads to the stool becomes hard and dry. In summary, OIBD is the consequence of reduced gastrointestinal motility, increased absorption of fluids from the gut and decreased epithelial secretion.

\section{Dyspepsia}

Dysfunction of the upper gastrointestinal tract (esophagus, stomach and duodenum) often manifests as dyspepsia. Dyspepsia represents a constellation of symptoms rather than a single disease entity. Its diverse symptoms may be expressed as epigastric pain, anorexia, belching, heartburn, bloating, nausea and vomiting, post-prandial fullness, early satiety, and/or regurgitation [19].

Two types of dyspepsia may be diagnosed:

- Structural (organic) dyspepsia for which a structural change can be demonstrated, often due to acid-related disease such as a gastric ulcer. In advanced cancer patients, symptoms may arise from NSAID, corticosteroid and bisphosphonate administration.

- Functional dysmotility (non-ulcer dyspepsia) due to dysmotility and/or altered sensitivity of the upper GI tract affecting the esophagus, stomach and duodenum. Esophageal and gastroduodenal dysmotility can be differentiated.

In cancer patients, it may be iatrogenic (e.g.; opioid-induced delayed gastric emptying) and associated with disease-related complications like hepatomegaly or massive ascites. Furthermore, paraneoplastic visceral autonomic neuropathy seems to play an important role. Opioids and other drugs such as anticholinergics, tricyclic antidepressants, benzodiazepines, nitrates and calcium channel blockers may decrease lower esophageal sphincter tone and lead to reflux (GERD) that would be aggravated secondarily by delayed gastric emptying. Gastric secretory and motor activity may be also affected by chronic alcoholism, diabetes, uremia, anxiety and depression. Gastroparesis is a symptomatic chronic disorder characterized by impaired gastric emptying in the absence of a structural cause. This occurs as a component of paraneoplastic syndromes, most commonly in the course of small cell lung, breast, ovarian cancer, Hodgkin disease or multiple myeloma. In addition to opioid adversely affecting gastric emptying, other drugs such as anticholinergics, neuroleptics or tricyclic antidepressants can aggravate gastroparesis. Meanwhile, concurrent conditions such as diabetes, prior gastric surgery, and neuromuscular disorders may further impair gastric emptying. Lastly, gastric or pancreatic tumors can inflict a mechanical outlet obstruction.

Another component that might co-exist is gastroesophageal reflux disease (GERD) due to reflux of gastric contents into the esophagus, causing mucosal damage and heartburn.

The prevalence of functional dyspepsia is high in the normal population (24-34\%) and even higher in cancer patients (70\%) [20]. Opioids adversely affect the esophagus. This class of drugs impairs esophageal inhibitory innervation and so induces spastic esophageal dysfunc- 
tion while impairing lower esophageal relaxation, leading to swallowing difficulties (dysphagia). Opioids also reduce the lower esophageal sphincter (LES) pressure, thereby decreasing the barrier pressure between the stomach and the esophagus, producing acid-reflux symptoms. This effect is reversed by naloxone. Opioids inhibit gastric emptying, a product of enhanced gastric relaxation and heightened pyloric tone. This decrease in gastric emptying results from both central and peripheral effects, although a peripheral $\mu$-opioid receptor mechanism is dominant. Opioid administration increases duodenal motility by generating patterns of contractions resembling migrating motor complex (MMC) phase III patterns. Endorphins in humans decrease antral phasic pressure activity and increase pyloric phasic pressure activity and induce MMC III-like bursts of contractile activity in the proximal gut followed by motor quiescence. Exogenous and endogenous opioids impair gastric emptying [21, 22].

The evaluation of patients with functional dyspepsia and gastroparesis is based on a careful history taking and physical examination that allow differentiating between functional and structural dyspepsia and GERD. The symptoms of gastroparesis, as quantified by the Gastroparesis Cardinal Symptom Index (GCSI), consists of 9 symptoms, each graded from 0 (none) to 5 (very severe), divided into 3 subscales: postprandial fullness/early satiety, nausea/vomiting, and bloating [23]. Upper endoscopy is usually needed to exclude mechanical obstruction and to assess for mucosal lesions. It is recommended in patients with alarming symptoms e.g.; those suspected for gastrointestinal bleeding. Endoscopy may be also conducted when symptoms develop with NSAIDs administration and when treatment with antisecretory drugs or antacids is unsuccessful. Blood tests assessing complete blood count and biochemistry might be useful. An ultrasound or CT abdominal scan is helpful to assess for cancer spread. In some patients, solid phase gastric scintigraphic emptying studies or breath tests may be needed to confirm gastroparesis. Other investigations such as electrogastrography, antroduodenal manometry are infrequently used in cancer patients.

\section{Management of opioid-induced bowel dysfunction}

\subsection{The management of dyspepsia}

a. Non-pharmacological measures

Treatment should be directed at cause of symptoms. Functional dyspepsia may be treated with non-pharmacological measures and drugs. The former comprise explanation and education of patients and families. Advice on the diet may play an important role. Fatty foods should be avoided as lipids impair gastric emptying, while lipids entering the duodenum may aggravate impaired gastric accommodation and gastric hypersensitivity. Medications that may cause dyspepsia (e.g. NSAIDs) should be discontinued when possible [24].

b. Pharmacological approach

Pharmacological treatment is usually needed. First-line therapy for dyspepsia is usually acid suppression. Proton pomp inhibitors (PPIs) such as omeprazole, esomeprazole or pantopra- 
zole are used once daily in doses $20-40 \mathrm{mg}$, best given 30 minutes before breakfast. In cancer patients, prokinetic agents are commonly administered, aiming to counteract opioid-induced motility disorders.

Typically, metoclopramide is prescribed (commonly as $10 \mathrm{mg}$ t.i.d.) for patients with functional dyspepsia, especially when symptoms arise from gastroparesis. Metoclopramide works mostly in the upper GI tract through blocking dopaminergic receptors. As metoclopramide also acts centrally, its use is associated with the added risk of extra-pyramidal effects, particularly in younger patients and children. Metoclopramide also inhibits the cytochrome, CYP2D6 enzyme [25]. The most common adverse effects of metoclopramide are restlessness, drowsiness and fatigue. Concomitant use of antidepressants, such as tricyclics, selective serotonin reuptake inhibitors (SSRIs) and newer serotonin-noradrenalin reuptake inhibitors (venlafaxine, duloxetine), may aggravate the adverse effects of metoclopramide [26]. Extrapyramidal effects are unlikely to occur when using domperidone, which does not cross blood-brain barrier [27]. Cisapride is a $5 \mathrm{HT}_{4}$ receptor agonist, affecting the entire GI tract; however, its cardiotoxicity has limited use [28].

Itopride works through peripheral blocking dopaminergic receptors. It inhibits acetylcholinesterase and so increases acetylcholine levels. Itopride works through the whole GI tract. It is devoid of activity at $5-\mathrm{HT}_{4}$ and $5-\mathrm{HT}_{3}$ receptors. Itopride is metabolized through monooxidase system. Thus, it has no significant risk of pharmacokinetic interactions with other drugs. Itopride does not cross blood-brain barrier and in consequence does not induce extrapyramidal effects. The dose usually equals $50 \mathrm{mg}$ t. i. d. [29]

Prucalopride, a new prokinetic agent, is a highly selective $5 \mathrm{HT}_{4}$ receptor agonist that stimulates gut motility in vitro and in vivo. Prucalopride at $2-4 \mathrm{mg}$ daily accelerates whole gut, gastric, small bowel and colonic transit in constipated patients [30]. The recommended dose is 1-2 mg once daily. Prucalopride is used in managing chronic constipation predominantly in women, but has not been evaluated in gastroparesis as yet [31]. Treatment is usually welltolerated; typical adverse effects are headaches (present in $25-30 \%$ of treated patients), nausea (12-24\%), abdominal pain or cramps (16-23\%) and diarrhea (12-19\%) [32]. Both itopride and prucapolpride appear safe relative to cardiac function.

Linaclotide is a minimally absorbed peptide guanylate cyclase-C agonist that appears quite effective for chronic constipation and the irritable bowel syndrome [33,34]. It looks promising in the treatment of gastroparesis and so may have a role in OBID.

Lubiprostone, a bicyclic fatty acid derived from prostaglandin E1, acts by specifically activating chloride channels on the apical aspect of gastrointestinal epithelial cells, producing a chloride-rich fluid secretion. These secretions soften the stool, increase intestinal motility, and so promote spontaneous bowel movements. Lubiprostone thus has value in treating functional constipation.

\subsection{Oral and rectal laxatives for Opioid-induced Bowel Dysfunction}

General measures to be taken in patients with OIBD and OIC include the assessment and applying prophylactic measures matched to the patient's general condition [35]. Change of 
diet (increased food and fluid intake), more physical activity, assuming a sitting position during bowel movement and obtaining privacy during defecation process are recommended [36]. Patients treated with opioids should be considered for prokinetic administration [37]. Any reversible causes such as hypercalcaemia should also be treated. Discontinuing or decreasing doses of drugs that may aggravate constipation (e.g. tricyclics, neuroleptics, anticholinergics) should also be considered. Patients and families should be educated about the means to prevent and treat OIBD [9].

In most patients with OIBD, laxatives are necessary. The general recommendation is to combine orally administered osmotic agents - usually lactulose or macrogol (PEG - polyethylene glycol) which have an osmotic effect in the colon [10] with stimulants activating on neurons in the myenteric and submucosal plexus in colon and reducing absorption of water and electrolytes from the intraluminal contents: anthracenes (senna), polyphenolics (bisacodyl) or sodium picosulphate. Unfortunately, these drugs exhibit limited efficacy in patients suffering from OIBD. Moreover, they may cause several adverse effects and must be administered on a regular basis [38]. Other classes of laxatives are faecal lubricants (liquid paraffin), stool softeners (surfactants: sodium docusate); however, they are usually ineffective when administered alone [39]. The use of bulk-forming agents such as fibre, bran, methylcellulose and psyllium seeds has limited role in patients with advanced constipation and warrant ingesting adequate fluids (at least 2 liters per day) [40-42]. Castor oil is not recommended due to its sudden stimulating effect on bowel motility and the risk of developing severe abdominal cramps [43]. If oral laxatives are found to be ineffective, rectal treatment should be considered.

Rectal laxatives comprise suppositories increasing intestinal motility through direct stimulation of the nerve endings in the myenteric ganglia of the colon, thus inducing peristalsis (bisacodyl) or using osmotic drugs (glycerol), which act by irritating the rectal mucosa and also enhance the colonic motility that subsequently triggers the defecation reflex. The next step if these agents prove ineffective is rectal enemas, either as normal saline (100-200 ml) or phosphates (120-150 ml).

The management of faecal impaction depends on the severity of symptoms (rectal pain, abdominal colicky pain, protruding hard faeces and faecal leakage). If the symptoms are not severe in case of soft faeces, administer bisacodyl 10-20 mg once daily either rectally or orally until bowel movements are achieved. If hard faeces are present, use glycerol and bisacodyl suppositories or osmotic enemas. Enemas of arachis oil $(130 \mathrm{ml})$ or of decussate sodium $(100 \mathrm{ml})$ followed by a phosphate enema next day may be appropriate. Macrogol (PEG) reduces the need for digital disimpaction. Digital stool evacuation may be necessary in cases of severe symptoms, when neither oral nor rectal treatment gives a desired effect and faecal impaction is not relieved, causing significant distress to the patient. As the procedure is quite painful and distressing, it should be performed with great caution and only when necessary and sometimes necessitating intravenous sedation with midazolam combined with opioids plus topical analgesics [44].

Polyethylene glycol (PEG) and sodium picosulphate are more effective than lactulose in OIC in cancer pain patients [45]. PEG specifically appears to be more effective than lactulose in 
terms of weekly bowel movement frequency, patient satisfaction, ease of defecation and reduced constipation symptoms with similar treatment tolerance and slightly higher lactulose costs [46]. For palliative care patients, different laxative regimens have no real differences. Overall, there is limited efficacy of traditional laxatives; well-done randomised controlled trials are lacking [47].

\subsection{Opioid switch}

The possibility of opioid switch for OIBD should be considered as one of the available treatment options. Opioids, which seem to be more often associated with constipation, are codeine and dihydrocodeine (opioids for mild to moderate pain), morphine, oxycodone and hydromorphone (opioids for moderate to severe pain). These opioids may be switched to other opioids belonging to the same group but having less constipating effect: codeine or dihydrocodeine may be switched to tramadol; morphine, oxycodone or hydromorphone to transdermal opioids (fentanyl, buprenorphine) or to methadone [48,49]. The most convincing evidence supporting the benefits of the opioid switch as regards constipation relief comes from the morphine to transdermal fentanyl switch [50-53]. In contrast to clinical studies, observational surveys do not provide evidence for advantages of transdermal fentanyl over other opioid analgesics with respect to bowel function. [54-55] Other studies report similar or less intense constipating effects with transdermal buprenorphine compared to $\mathrm{CR}$ morphine [56] and after a switch from morphine to methadone [57-59]. There may be a benefit to administering tramadol rather than small morphine doses [60-62] or dihydrocodeine [63] with respect to the constipation intensity. However, no differences were found in constipation in cancer patients with pain between transdermal opioids (buprenorphine and fentanyl) and oral controlled release hydromorphone [64].

\subsection{Targeted treatment of opioid-induced bowel dysfunction}

Few clinical studies compared the efficacy of different laxatives [65] and controlled studies are lacking [66]. Certainly traditional laxatives do not target the cause of OIBD, which is predominantly associated with opioid analgesics binding and activating $\mu$-opioid receptors in the GI tract [67]. Treatment directed at the cause of OIBD involves either using a combination of opioid analgesics with opioid receptor antagonists, which act both centrally and peripherally, or administering opioid receptor antagonists, which act exclusively peripherally. An important advantage of this approach is the fact that it is targeted treatment of OIBD and that it may be combined with oral laxatives, if necessary. Finally, this approach may eliminate the need for rectal measures, which patients tolerate poorly.

Apart from opioid antagonists with exclusively peripheral effects, opioid receptor antagonists with a central mode of action are naloxone, naltrexone and nalmefene. The majority of studies performed so far have used immediate release formulation of oral naloxone (IR naloxone). In spite of high IR naloxone efficacy in the treatment of OIBD, some patients experience opioid withdrawal symptoms and attenuation of analgesia, rendering IR naloxone less useful when administered alone [68-70]. Nalmefene [71] and nalmefene glucuronide [72] behave similarly. 


\subsection{Combined opioid receptor agonist with its antagonist}

One of methods to decrease the frequency of constipation in patients requiring strong opioids is using formulation composed of an opioid and opioid receptor antagonist. The formulation combining oxycodone and naloxone is available in the form of prolonged release (PR) tablets containing both drugs in the ratio of 2:1 (PR oxycodone/PR naloxone 5 $\mathrm{mg} / 2.5 \mathrm{mg}, 10 \mathrm{mg} / 5 \mathrm{mg}, 20 \mathrm{mg} / 10 \mathrm{mg}, 40 \mathrm{mg} / 20 \mathrm{mg}$ ) [73]. The optimal 2:1 ratio of PR oxycodone/PR naloxone tablets was demonstrated in a phase II study rendering effective analgesia and improvement in bowel function with good treatment toleration in patients with severe chronic pain [74]. PR oxycodone/PR naloxone is registered for the indication of severe pain, which may only be successfully treated with opioid analgesics. In this formulation, naloxone counteracts the development of OIBD through inhibition of oxycodone effect on opioid receptors in the gut wall [75]. The starting PR oxycodone/PR naloxone doses in opioid-naive patients is $5 \mathrm{mg} / 2.5 \mathrm{mg}$ b.i.d. Patients unsuccessfully treated with opioids for mild to moderate pain (tramadol, codeine, dihydrocodeine) may start with the dose $10 \mathrm{mg} / 5 \mathrm{mg}$ b.i.d. When rotating from other opioids for moderate to severe pain to $\mathrm{PR}$ oxycodone/PR naloxone, the starting dose is established individually depending on the amount of previously administered opioid, analgesia and adverse effects. The maximal daily dose of PR oxycodone/PR naloxone recommended equals $40 \mathrm{mg} /$ $20 \mathrm{mg}$ twice daily. However, in a study conducted in cancer patients with pain higher daily doses up to $120 \mathrm{mg} / 60 \mathrm{mg}$ were effective and well-tolerated while symptoms of OIBD were decreased, compared to PR oxycodone administered alone [76].

Following oral administration, oxycodone displays high bioavailability (60 - 87\%) and provides effective analgesia [77,78]. Naloxone exhibits low bioavailability after oral administration $(<2 \%)$ and undergoes extensive first-pass metabolism in the liver with the formation of naloxone-3-glucuronide [79]. Analgesic effect is not reversed by naloxone and no symptoms of opioid withdrawal occur. This effect of orally administered naloxone depends on normal liver function. Thus, any hepatic impairment should be carefully considered. In patients suffering from decompensated liver disease, PR oxycodone/PR naloxone administration is not recommended. There is a clinically observed difference between the administration of IR and PR formulations of naloxone. IR naloxone in some patients may attenuate analgesia or induce opioid withdrawal symptoms. The PR naloxone formulation prevents saturation of hepatic enzyme system responsible for naloxone metabolism and reduces the risk of opioid antagonism in the CNS [3].

PR oxycodone/PR naloxone provides similar analgesic efficacy to oxycodone with improvement in bowel function, a lower consumption of laxatives and more frequent spontaneous bowel movements [82]. during treatment with PR oxycodone/PR naloxone in comparison to PR oxycodone therapy [80-82]. Long-term therapy (up to 52 weeks) with PR oxycodone/PR naloxone in daily doses up to $80 \mathrm{mg} / 40 \mathrm{mg}$ appears effective and safe [83]. Analgesia is effective while bowel function and quality of life improved with PR oxycodone/PR naloxone (20 mg/10 mg to $40 \mathrm{mg} / 20 \mathrm{mg}$ ) treatment in patients with severe neuropathic non-malignant pain [84]. Even at quite high doses, PR oxycodone/PR naloxone doses exhibited a benefit compared to PR oxycodone administered alone [85]. PR oxycodone/PR naloxone in doses up 
to $120 \mathrm{mg} / 60 \mathrm{mg}$ per day provides effective analgesia while improving bowel function [76]. Adverse effects of PR oxycodone/PR naloxone and PR oxycodone are similar; the frequency of diarrhea is slightly higher in PR oxycodone/PR naloxone compared to PR oxycodone administered alone (5.2\% vs. 2.6\%) [81]. However, PR oxycodone/PR naloxone less frequency induces nausea (6.3\% vs. $10.5 \%)$, vomiting (1.3\% vs. $4.3 \%)$, abdominal pain (1.3\% vs. $4.3 \%)$ and dyspepsia $(0.6 \%$ vs. $2.5 \%)$ in comparison to PR oxycodone administered alone [82]. These differences might be explained by naloxone antagonist effect on gastric and gut opioid receptors and in consequence, naloxone prokinetic properties [86]. PR oxycodone/PR naloxone studies were performed mainly in patients with chronic, non-malignant pain [8083,85,89]. Opioid switch to PR oxycodone/PR naloxone for cancer patients generally provides adequate analgesia and improved bowel function [87], but in some requiring heightened analgesia, very high doses of PR up to $240 \mathrm{mg}$ per day oxycodone administered alone may be necessary[88].

The contraindications for PR oxycodone/PR naloxone comprise bowel obstruction, acute abdominal conditions, diarrhea and an allergy to the drug. PR oxycodone/PR naloxone is available in several European countries. One pack contains $60 \mathrm{PR}$ oxycodone/PR naloxone tablets of $5 \mathrm{mg} / 2.5 \mathrm{mg}, 10 \mathrm{mg} / 5 \mathrm{mg}, 20 \mathrm{mg} / 10 \mathrm{mg}$, $40 \mathrm{mg} / 20 \mathrm{mg}$ strength. Direct treatment costs for PR oxycodone/PR naloxone in patients with moderate-to-severe non-malignant pain and opioid-induced constipation is slightly higher compared to oxycodone PR. When analysing constipation treatment costs and benefits of PR oxycodone/PR naloxone in terms of improved quality-adjusted life-years, PR oxycodone/PR naloxone appears to be cost-effective option in the UK [90]. Government and other insurance schemes however may not reimburse PR oxycodone/PR naloxone tablets.

\subsection{Purely peripherally acting opioid receptor antagonists}

Methylnaltrexone (MNTX), a derivative of naltrexone, is a peripheral $\mu$-opioid receptor antagonist, which does not cross blood-brain barrier [91]. Because of its low oral bioavailability, MNTX is administered subcutaneously or intravenously [92]. However, MNTX taken orally prevents the delay in oro-ceacal transit time that follows intravenous morphine administration [93]. MNTX plasma half-life equals 105 to 140 minutes. 50\% is excreted unchanged in the urine. MNTX is a weak CYP2D6 inhibitor with no significant drug interactions [94]. MNTX is used to treat OIC in adult patients with advanced diseases when constipation does not respond to conventional oral laxatives. The drug is available in ampoules containing $12 \mathrm{mg}$ MNTX bromide in the volume of $0.6 \mathrm{ml}$ and is applied via subcutaneous injections. The recommended single MNTX dose is $8 \mathrm{mg}$ in patients with body weight $38-61 \mathrm{~kg}$ or $12 \mathrm{mg}$ if the body mass is $62-114 \mathrm{~kg}$ [95]. Those falling outside of this range should receive a dose of $0.15 \mathrm{mg} / \mathrm{kg}$. No dose adjustment is necessary for patients with mild to moderate hepatic or renal impairment. However, in patients with severe renal failure (creatinine clearance $<30 \mathrm{~mL} / \mathrm{min}$ ) the MNTX dose should be reduced by one-half [96].

A bowel movement within $4 \mathrm{~h}$ after MNTX injection is observed in 50-60\% patients (the median time to bowel movement after the drug administration is 30 minutes). If no therapeutic effect is observed, the injection may be repeated every other day. MNTX adverse effects 
comprise abdominal pain ( $28 \%$ of the treated patients), flatulence $(13 \%)$, nausea $(11 \%)$, dizziness (7\%) and diarrhoea (5\%) [16]. However, the administration of MNTX may be associated with an increased risk of gastrointestinal perforation in patients with diseases that decrease gut wall integrity (cancer, peptic ulceration and Ogilvie's syndrome) or on concomitant medications (NSAIDs, bevacizumab). GI perforation occur at different possible locations (duodenum, small and large bowel). A possible contributing factor might be the prokinetic effect of MNTX. It is not known if dose and duration of the treatment with MNTX relate to this complication [95]. As MNTX does not cross the blood-brain barrier, there is no attenuation of analgesia nor is there an opioid withdrawal syndrome [17]. The use of MNTX is contraindicated in patients with mechanical bowel obstruction, in acute abdominal conditions and in case of allergy to the drug. MNTX may be used in palliative care patients with OIBD not amenable to the treatment with oral laxatives. Several clinical studies have demonstrated the effectiveness of MNTX in patients with advanced diseases and with OIBD $[16,17,95,96,98-100]$. Peripherally active opioid receptor antagonists in the treatment of OIBD are effective and safe in [101-4]. Long-term efficacy and safety of opioid antagonists is not yet clearly established, in part due to a limited number of randomized studies [105-6].].

The Expert Working Group of the Polish Association for Palliative Medicine developed a three step ladder for the management of OIC (Fig. 1) [43]. This updated version of the ladder takes into account new therapies directed at the underlying mechanism of OIBD [107].

Invasive procedures of step III:

- Rectal enema

- Manual evacuation**

3

Drug(s) of step II:

- Rectal suppositories

- PAMORA*

Constipation persists or intensifies

(Methylnaltrexone - sc)

Drug(s) of step I (oral):

- Osmotic agents:

2 lactulose or macrogol

- Stimulants: antranoids or poliphenolics

- Oxycodone/naloxone

Constipation persists or intensifies

1

\begin{abstract}
* PAMORA-peripherally acting mu-opioid receptor antagonists (methylnaltrexone) indicated for patients who do not respond to traditional oral laxatives without bowel obstruction and acute abdominal illness; ** This procedure should be used only when other measures fail and the faecal impaction causes significant pain and distress for the patient. It should be proceeded by a sedative and analgesics (local and systemic) administration that provide effective relief of severe pain and distress associated with manual stool evacuation; sc - subcutaneous
\end{abstract}

Figure 1. The three-step ladder of the management of opioid-induced constipation $[43,107]$ 
At the first step traditional oral laxatives and/or PR oxycodone/PR naloxone may be considered. PR oxycodone/PR naloxone targets the source of OIBD (prevention and treatment) as PR naloxone blocks opioid receptors in the gut and PR oxycodone provides effective analgesia. PR oxycodone/PR naloxone may be considered in cancer pain patients who are at high risk of OIBD development such as those with GI tumors, patients who require combined treatment with opioids and other drugs disturbing normal bowel function, e.g. advanced cancer patients. At the second step subcutaneous administration of MNTX may be considered when traditional oral laxatives are ineffective, which may allow avoiding invasive and often painful invasive procedures at step 3 of the ladder.

\section{Conclusions}

OIBD in patients diagnosed with chronic diseases is a challenging problem that health care providers often underestimate. This is particularly important in patients regularly receiving opioids for pain or other indications. Thanks to newly introduced drugs that target the cause of OIBD, a more effective therapy is available. The experience with MNTX and PR oxycodone/PR naloxone in patients suffering from OIBD is promising. Further clinical studies are needed to develop more effective guidelines for the management of OIBD and to establish more precisely the role of opioid receptor antagonists. The role of opioid receptor antagonists as potential antiemetic and prokinetic agents should be further explored as suggested by experimental studies in animals. The cost-benefit from new therapies must be carefully considered; overall resources may actually be saved from reduced use of traditional laxatives. The most important advantage of targeted therapies is to decrease patient suffering from OIBD, substantial reduce the need to perform invasive rectal procedures and most importantly, improve quality of life.

\section{Author details}

Wojciech Leppert

Address all correspondence to: wojciechleppert@wp.pl

Chair and Department of Palliative Medicine, Poznan University of Medical Sciences, Poznan, Poland

\section{References}

[1] Ueberral MA, Mueller-Schwefe G. Opioid-induced constipation - a frequent and distressing side effect in daily practice affecting oral and transdermal opioid applications. Eur J Pain 2006; 10: S172. 
[2] Bell TJ, Panchal SJ, Miaskowski C, Bolge SC, Milanova T, Williamson R. The Prevalence, Severity, and Impact of Opioid-Induced Bowel Dysfunction: Results of a US and European Patient Survey (PROBE 1). Pain Med 2009; 10: 35-42.

[3] Reimer K, Hopp M, Zenz M et al. Meeting the Challenges of Opioid-Induced Constipation in Chronic Pain Management - A Novel Approach. Pharmacology 2009; 83: $10-17$.

[4] Davis MP. The opioid bowel syndrome: a review of pathophysiology and treatment. J Opioid Manage 2005; 1: 153-161.

[5] Holzer P. Treatment of opioid-induced gut dysfunction. Expert Opin Investig Drugs 2007; 16: 181-194.

[6] Holzer P. Opioids and opioid receptors in the myenteric nervous system: from a problem in opioid analgesia to a possible new prokinetic therapy in humans. Neurosci Lett 2004; 361: 192-195.

[7] Shook JE, Pelton JT, Hruby VJ, Burks TF. Peptide opioid antagonist separates peripheral and central opioid antitransit effects. J Pharmacol Exp Ther 1987; 243: 492-500.

[8] Sykes NP. Constipation and diarrhoea. In: Doyle D, Hanks G, Cherny N, Calman K, eds. Oxford Textbook of Palliative Medicine. Oxford University Press; Oxford 2004, pp. 483-496.

[9] Basta S, Anderson DL. Mechanisms and Management of Constipation in the Cancer Patient. J Pharmaceut Care Pain Symptom Control 1998; 6: 21-40.

[10] Potter J, Wagg A. Management of bowel problems in older people: an update. Clin Med 2005; 5: 289-295.

[11] Mumford SP. Can high fibre diets improve the bowel function in patients on radiotherapy ward? In: Twycross RG, Lack SA eds. Control of alimentary symptoms in far advanced cancer. Churchill Livingstone; Edinburgh 1986: 183.

[12] Porecca F, Cowan A, Raffa RB, Tallarida RJ. Ketazocines and morphine: effects on gastrointestinal transit after central and peripheral administration. Life Sci 1983; 32: 1785-1790.

[13] Parolado D, Sala M, Gori E. Effect of intracerebroventricular administration of morphine upon intestinal motility in rat and its antagonism with naloxone. Eur J Pharmacol 1977; 46: 329-338.

[14] Stewart JJ, Weisbrodt NW, Burks TF. Central and peripheral action of morphine on intestinal transit. J Pharmacol Exp Ther 1978; 205: 547-555.

[15] Thörn SE, Wattwil M, Lindberg G, Säwe J. Systemic and central effects of morphine on gastrointestinal motility. Acta Anaesthesiol Scand 1996; 40: 177-186. 
[16] Thomas J, Karver S, Cooney GA et al. Methylnaltrexone for Opioid-Induced Constipation in Advanced Illness. N Engl J Med 2008; 358: 2332-2343.

[17] Slatkin N, Thomas J, Lipman AG et al. Methylnaltrexone for Treatment of OpioidInduced Constipation in Advanced Illness Patients. J Support Oncol 2009; 7: 39-46.

[18] Wood JD, Galligan JJ. Function of opioids in the enteric nervous system. Neurogastroenterol Motil 2004; 16 (suppl. 2): 181-194.

[19] Davies MP, Walsh D. Gastrointestinal motility disorders. In: Ripamonti C, Bruera E, eds. Gastrointestinal Symptoms in Advanced Cancer Patients. Oxford University Press; Oxford 2002, pp. 127-168.

[20] Regnard C. Dysphagia, dyspepsia, and hiccup. In: Hanks G,Cherny NI, Christiakis NA, Fallon M, Kaasa S, Portenoy RK, eds. Oxford Textbook of Palliative Medicine. Oxford University Press; Oxford 2011, pp. 812-833.

[21] Narducci F, Bassotti G, Granata MT, Gaburri M, Farroni F, Palumbo R, Morelli A. Functional dyspepsia and chronic idiopathic gastric stasis. Role of endogenous opiates. Arch Intern Med 1986; 146: 716-720.

[22] Aktas A, Caner B, Ozturk F, Bayhan H, Narin Y, Mentes T. The effect of trimebutine maleate on gastric emptying in patients with non-ulcer dyspepsia. Ann Nucl Med 1999; 13: 231-234.

[23] Revicki DA, Rentz AM, Dubois D, Kahrilas P, Stanghellini V, Talley NJ, Tack J. Development and validation of a patient-assessed gastroparesis symptom severity measure: the Gastroparesis Cardinal Symptom Index. Aliment Pharm Ther 2003; 18: 141-150.

[24] Wo JM, Parkman HP. Motility and Functional Disorders of the Stomach: Diagnosis and Management of Functional Dyspepsia and Gastroparesis. Pract Gastroenterol 2006; 30: 23-48.

[25] Desta Z, Wu GM, Morocho AM, Flockhart DA. The gastroprokinetic and antiemetic drug metoclopramide is a substrate and inhibitor of cytochrome P450 2D6. Drug Metabol Dis 2002; 30: 336-343.

[26] Glare P, Nikolova T, Tickoo R, Miller J, Bras M. An overview of anti-emetic medications and the considerations for their use in palliative care. Eur J Palliat Care 2012; 19: 162-167.

[27] Twycross R, Wilcock A. Gastro-intestinal system. In: Twycross R, Wilcock A (Editors-in-Chief). Palliative Care Formulary. Fourth Edition. Palliativedrugs.com Ltd. Nottingham 2012, pp. 1-54.

[28] Potet F, Bouyssou T, Escande D, Baro I. Gastrointestinal prokinetic drugs have different affinity for the human cardiac ether-a-gogo $\mathrm{K}(+)$ channel. J Pharmacol Exp Ther 2001; 299: 1007-1012. 
[29] Chojnacki J. Itopride in the treatment of kinetic disorders of gastrointestinal tract (in Polish). Przegl Gastroentorol 2011; 6: 139-145.

[30] Bouras EP, Camilleri M, Burton DD, Thomforde G, McKinzie S, Zinsmeister AR. Prucalopride accelerates gastrointestinal and colonic transit in patients with constipation without a rectal evacuation disorder. Gastroenterology 2001; 120: 354-360.

[31] Tack J, van Outryve M, Beyens G, Kerstens R, Vandeplassche L. Prucalopride (Resolor) in the treatment of severe chronic constipation in patients dissatisfied with laxatives. Gut 2009; 58: 357-365.

[32] Quigley EMM. Prucalopride: safety, efficacy and potential applications. Ther Adv Gastroenterol 2012; 5: 23-30.

[33] Müller-Lissner S. Pharmacokinetic and pharmacodynamic considerations for the current chronic constipation treatments. Exp Opin Drug Metabol Toxicol 2013; 9: 391-401.

[34] Bushby RW, Kessler MM, Bartolini WP. et al. Pharmacologic properties, metabolism, and disposition of linaclotide, a novel therapeutic peptide approved for the treatment of irritable bowel syndrome with constipation and chronic idiopathic constipation. J Pharmacol Exp Ther 2013; 344: 196-206.

[35] Benson AB, Stein R. Diarrhoea and Constipation: Supportive Oncology Management. In: Ettinger DS, ed. Supportive Care in Cancer Therapy. Humana Press; New York 2009, pp. 213-225.

[36] Klaschik E, Nauck F, Ostgathe C. Constipation - modern laxative therapy. Support Care Cancer 2003; 11: 679-685.

[37] Bruera E, Brenneis C, Michand M, MacDonald N. Continuous subcutaneous infusion of metoclopramide for treatment of narcotic bowel syndrome. Cancer Treat Rep 1987; 71: 1121-1122.

[38] Larkin PJ, Sykes NP, Centeno C et al. The management of constipation in palliative care: clinical practice recommendations. Palliat Med 2008; 22: 796-807.

[39] Leppert $W$. The management of patients with gastrointestinal symptoms in palliative care (in Polish). Terapia 2011; 19: 59-66.

[40] Mancini I, Bruera E. Constipation. In: Ripamonti C, Bruera E, eds. Gastrointestinal symptoms in advanced cancer patients. Oxford University Press; Oxford 2004: pp. 193-206.

[41] Sykes NP. Current approaches to the management of constipation. Cancer Surv 1994; 21: 137-146.

[42] Mancini I, Bruera E. Constipation in advanced cancer patients. Support Care Cancer 1998; 6: 356-364. 
[43] Leppert W, Dzierzanowski T, Cialkowska-Rysz A, Jarosz J, Pyszkowska J, Stachowiak A. The management of constipation in palliative medicine - recommendations of the Expert Working Group of the Polish Association for Palliative Medicine (in Polish). Med Paliat 2009; 1: 1-10.

[44] Twycross R, Wilcock A, Toller CS. Faecal Impaction. In: Twycross R, Wilcock A, Toller CS. Symptom Management in Advanced Cancer. Palliativedrugs.com Ltd, Nottingham 2009, pp. 119-120.

[45] Wirz S, Nadstawek J, Elsen C, Junker U, Wartenberg HC. Laxative management in ambulatory cancer patients on opioid therapy: a prospective, open-label investigation of polyethylene glycol, sodium picosulphate and lactulose. Eur J Cancer Care 2012: 21: 131-140.

[46] Belsey D, Geraint M, Dixon TA. Systematic review and meta analysis: polyethylene glycol in adults with non-organic constipation. Int J Clin Pract 2010; 64: 944-955.

[47] Miles CL, Fellowes D, Goodman ML, Wilkinson S. Laxatives for the management of constipation in palliative care patients. Cochrane Database Syst Rev 2011; (1): CD003448.

[48] Mercadante S, Bruera E. Opioid switching: a systematic and critical review. Cancer Treat Rev 2006; 32: 304-315.

[49] Leppert W. Progress in pharmacological pain treatment with opioid analgesics (in Polish). Wspolcz Onkol 2009; 13: 66-73.

[50] Ahmedzai S, Brooks D. Transdermal Fentanyl versus Sustained-Release Oral Morphine in Cancer Pain: Preference, Efficacy and Quality of Life. J Pain Symptom Manage 1997; 13: 254-261.

[51] Haazen L, Noorduin H, Megens A, Meert T. The constipation-inducing potential of morphine and transdermal fentanyl. Eur J Pain 1999; 3 (Suppl. A): 9-15.

[52] Hunt R, Fazekas B, Thorne D, Brooksbank M. A comparison of subcutaneous morphine and fentanyl in hospice cancer patients. J Pain Symptom Manage 1999; 18: $111-$ 119.

[53] Tassinari D, Sartori S, Tamburini E et al. Adverse Effects of Transdermal Opiates Treating Moderate-Severe Cancer Pain in Comparison to Long-Acting Morphine: A Meta-Analysis and Systematic Review of the Literature. J Palliat Med 2008; 11: 492502.

[54] Rosti G, Gatti A, Costantini A, Sabato AF, Zucco F. Opioid-related bowel dysfunction: prevalence and identification of predictive factors in a large sample of Italian patients on chronic treatment. Eur Rev Med Pharmacol Sci 2010; 14: 1045-1050.

[55] Weschules DJ, Bain KT, Reifsnyder J, et al. Toward Evidence-Based Prescribing at End of Life: A Comparative Analysis of Sustained-Release Morphine, Oxycodone, 
and Transdermal Fentanyl, with Pain, Constipation, and Caregiver Interaction Outcomes in Hospice Patients. Pain Med 2006; 7: 320-329.

[56] Bach V, Kamp-Jensen M, Jensen N-H, Eriksen J. Buprenorphine and sustained release oral morphine - effect and side-effects in chronic use. Pain Clin 1991; 4: 87-93.

[57] Mancini IL, Hanson J, Neumann CM, Bruera E. Opioid type and other clinical predictors of laxative dose in advanced cancer patients: a retrospective study. J Palliat Med 2000; 3: 49-56.

[58] Daeninck PJ, Bruera E. Reduction in constipation and laxative requirements following opioid rotation to methadone: a report of four cases. J Pain Symptom Manage 1999; 18: 303-309.

[59] Mercadante S, Casuccio A, Fulfaro F et al. Switching From Morphine to Methadone to Improve Analgesia and Tolerability in Cancer Patients: A Prospective Study. J Clin Oncol 2001; 19: 2898-2904.

[60] Grond S, Radbruch L, Meuser T, Loick G, Sabatowski R, Lehmann KA. High-Dose Tramadol in Comparison to Low-Dose Morphine for Cancer Pain Relief. J Pain Symptom Manage 1999; 18: 174-179.

[61] Duggan AK. The cost of constipation in morphine patients and the economic possibilities with tramadol. Br J Med Econom 1995; 9: 21-29.

[62] Leppert W. Analgesic efficacy and side effects of oral tramadol and morphine administered orally in the treatment of cancer pain. Nowotwory 2001; 51: 257-266.

[63] Leppert W, Majkowicz M. Assessment of analgesia and adverse effects of controlled release tramadol and dihydrocodeine in patients with cancer pain - based on a modified ESAS. Wspolcz Onkol 2008; 12: 246-254.

[64] Wirz S, Witmmann M, Schenk M et al. Gastrointestinal symptoms under opioid therapy: A prospective comparison of oral sustained-release hydromorphone, transdermal fentanyl, and transdermal buprenorphine. Eur J Pain 2009; 13: 737-743.

[65] Sykes NP. A clinical comparison of laxatives in a hospice. Palliat Med 1991; 5: 307314.

[66] Miles CL, Fellowes D, Goodman ML, Wilkinson S. Laxatives for the management of constipation in palliative care patients. Cochrane Database Syst Rev 2006; 4: CD003448.

[67] Holzer P, Ahmedzai SH, Niederle $\mathrm{N}$ et al. Opioid-induced bowel dysfunction in cancer-related pain: causes, consequences, and a novel approach for its management. J Opioid Manage 2009; 5: 145-195.

[68] Sykes NP. An investigation of the ability of oral naloxone to correct opioid-related constipation in patients with advanced cancer. Palliat Med 1996; 10: 135-144. 
[69] Liu M, Wittbrodt E. Low-dose oral naloxone reverses opioid-induced constipation and analgesia. J Pain Symptom Manage 2002; 23: 48-53.

[70] Meissner W, Schimdt U, Hartmann M et al. Oral naloxone reverses opioid-induced constipation. Pain 2000; 84: 105-109.

[71] Glass PS, Jhaveri RM, Smith LR. Comparison of potency and duration of action of nalmefene and naloxone. Anesth Analg 1994; 78: 536-541.

[72] Cheskin LJ, Chami TN, Johnson RE et al. Assessment of nalmefene glucuronide as a selective gut opioid antagonist. Drug Alcohol Depend 1995; 39: 151-154.

[73] Nadstawek J, Leyendecker P, Hopp M et al. Patient assessment of a novel therapeutic approach for the treatment of severe, chronic pain. Int J Clin Pract 2008; 62: 11591167.

[74] Leyendecker P, Hopp M, Bosse B et al. Bowel Function Index (BFI), a new validated questionnaire for assessing opioid induced constipation. Proceedings of the IASP Congress on Pain, Glasgow; 2008.

[75] Anonim. Oxycodone/naloxone prolonged release tablets, questions and answers. Paineurope supplement. February 2009.

[76] Ahmedzai SH, Nauck F, Bar-Sela G, Bosse B, Leyendecker P, Hopp M. A randomized, double-blind, active-controlled, double-dummy, parallel-group study to determine the safety and efficacy of oxycodone/naloxone prolonged-release tablets in patients with moderate/severe, chronic cancer pain. Palliat Med 2012; 26: 50-60.

[77] Kalso E. Oxycodone. J Pain Symptom Manage 2005; 29 (5S): S47-S56.

[78] Biancofiore G. Oxycodone controlled release in cancer pain management. Therap Clinic Risk Manage 2006; 2: 228-234.

[79] Fishman J, Roffwarg H, Helman L. Disposition of naloxone-7,8-3H in normal and narcotic-dependent men. J Pharmacol Exp Ther 1973; 187: 575-580.

[80] Müller-Lissner S, Leyendecker P, Hopp M, Ruckes C, Fleischer W, Reimer K. Oral prolonged release (PR) oxycodone/naloxone combination reduces opioid-induced bowel dysfunction (OIBD) in patients with severe chronic pain. Eur J Pain 2007; 11 (S82): abstract 189.

[81] Vondrackova D, Leyendecker P, Meissner W et al. Analgesic Efficacy and Safety of Oxycodone in Combination With Naloxone as Prolonged Release Tablets in Patients With Moderate to Severe Chronic Pain. J Pain 2008; 9: 1144-1154.

[82] Simpson K, Leyendecker P, Hopp M et al. Fixed-ratio combination oxycodone/naloxone compared with oxycodone alone for the relief of opioid-induced constipation in moderate-to-severe noncancer pain. Curr Med Res Opin 2008; 24: 3503-3512. 
[83] Sandner-Kiesling A, Leyendecker P, Hopp M et al. Long-term efficacy and safety of combined prolonged-release oxycodone and naloxone in the management of noncancer chronic pain. Int J Clin Pract 2010; 64: 763-774.

[84] Hermanns K, Junker U, Nolte T. Prolonged-release oxycodone/naloxone in the treatment of neuropathic pain - results from a large observational study. Exp Opin Pharmacother 2012; 13: 299-311.

[85] Löwenstein O, Leyendecker P, Hopp $\mathrm{M}$ et al. Combined prolonged release oxycodone and naloxone improves bowel function in patients receiving opioids for moderate-to-severe non-malignant chronic pain: a randomized controlled trial. Expert Opin Pharmacother 2009; 10: 531-453.

[86] Schang JC, Devroede G. Beneficial effects of naloxone in a patient with intestinal pseudoobstruction. Am J Gastroenterol 1985; 80: 407-411.

[87] Clemens KE, Quednau I, Klaschik E. Bowel function during pain therapy with oxycodone/naloxone prolonged-release tablets in patients with advanced cancer. Int J Clin Pract 2011; 65: 472-478.

[88] Mercadante S, Ferrera P, Adile C. High doses of oxycodone-naloxone combination may provide poor analgesia. Support Care Cancer 2011; 19: 1471-1472.

[89] Meissner W, Leyendecker P, Meuller-Lissner S et al. A randomised controlled trial with prolonged-release oral oxycodone and naloxone to prevent and reverse opioidinduced constipation. Eur J Pain 2009; 13: 56-64.

[90] Dunlop W, Uhl R, Khan I, Taylor A, Barton G. Quality of life benefits and cost impact of prolonged release oxycodone/naloxone versus prolonged release oxycodone in patients with moderate-to-severe non-malignant pain and opioid-induced constipation: a UK cost-utility analysis. J Med Econ 2012; 15: 564-575.

[91] Shaiova L, Rim F, Friedman D, Jahdi M. A review of methylnaltrexone, a peripheral opioid receptor antagonist, and its role in opioid-induced constipation. Palliat Support Care 2007; 5: 161-166.

[92] Yuan CS. Clinical Status of Methylnaltrexone, A New Agent to Prevent and Manage Opioid-Induced Side Effects. J Support Oncol 2004; 2: 111-122.

[93] Yuan CS, Foss JF, Osinski J, Toledano A, Roizen MF, Moss J. The safety and efficacy of oral Clinical methylnaltrexone in preventing morphine-induced delay in oral-cecal transit time. Clin Pharmacol Ther 1997; 61: 467-475.

[94] Abarca FM, Saclarides TJ, Brand MI. A Review of the Treatment of Opioid-induced Constipation with Methylnaltrexone Bromide. Clinical Medicine Insights: Therapeutics 2010; 2: 53-60.

[95] Portenoy RK, Thomas J, Moehl Boathwright ML. et al. Subcutaneous methylnaltrexone for the treatment of opioid-induced constipation in patients with advanced ill- 
ness: a double-blind, randomized, parallel group, dose-ranging study. J Pain Symptom Manage 2008; 35: 458-468.

[96] Chamberlain BH, Cross K, Winston JL et al. Methylnaltrexone Treatment of OpioidInduced Constipation in Patients with Advanced Illness. J Pain Symptom Manage 2009; 38: 683-690.

[97] Corken A, Green L, Greene P, Avigan M. Methylnatrexone and Gastrointestinal Perforation. J Pain Symptom Manage 2010; 40: e1-e3.

[98] Becker G, Galandi D, Blum HE. Peripherally Acting Opioid Antagonists in the Treatment of Opiate-Related Constipation: a Systematic Review. J Pain Symptom Manage 2007; 34: 547-565.

[99] Yuan CS. Methylnaltrexone mechanisms of action and side effects on opioid bowel dysfunction and of the opioid adverse effects. Ann Pharmacother 2007; 41: 984-993.

[100] Yuan CS, Foss JF, O'Connor M et al. Methylnaltrexone for Reversal of Constipation Due to Chronic Methadone Use: A Randomized Controlled Trial. JAMA 2000; 283: 367-372.

[101] McNicol E, Boyce DB, Schumann R, Carr D. Efficacy and Safety of Mu-Opioid Antagonists in the Treatment of Opioid-Induced Bowel Dysfunction: Systematic Review and Meta-analysis of Randomized Controlled Trials. Pain Med 2008; 9: 634659.

[102] McNicol ED, Boyce D, Schumann R, Carr DB. Mu-opioid antagonists for opioid-induced bowel dysfunction. Cochrane Database Syst Rev. 2008 Apr 16; (2):CD006332.

[103] Paulson DM, Kennedy DT, Donovick RA et al. Alvimopan: An oral, peripherally acting, mu-opioid receptor antagonist for the treatment of opioid-induced bowel dysfunction - a 21-day treatment-randomized trial. J Pain 2005; 6: 184-192.

[104] Leppert W. The role of opioid receptor antagonists in the treatment of opioid-induced constipation - a review. Adv Ther 2010; 27: 714-730.

[105] Leppert $\mathrm{W}$. The impact of opioid analgesics on the gastrointestinal tract function and the current management possibilities. Wspolcz Onkol 2012; 16: 125-131.

[106] Candy B, Jones L, Goodman ML, Drake R, Tookman A. Laxatives or methylnaltrexone for the management of constipation in palliative care patients. Cochrane Database Syst Rev 2011; 1: CD003448.

[107] Leppert W. The place of oxycodone/naloxone in chronic pain management. Wspolcz Onkol 2013; 17: 128-133 
